\title{
Enhancement of strength of adhesive bond between wood and metal using atmospheric plasma treatment
}

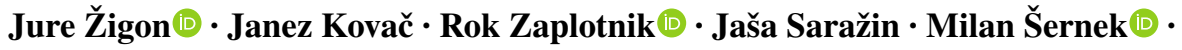 \\ Marko Petrič $(\mathbb{D} \cdot$ Sebastian Dahle $\mathbb{D}$
}

Received: 12 February 2020 / Accepted: 3 May 2020 / Published online: 14 May 2020

(C) The Author(s) 2020, corrected publication 2021

\begin{abstract}
Combinations of wood and metal are interesting hybrid composite materials, joining together the low density of wood with the stiffness and strength of metals. Different types of adhesives are used to connect wood and metal elements, but the compatibility between adhesives used and loadbearing materials must be sufficient, which often is challenging. In adhesive bonding technology, surface treatments are a crucial step in the process. In this study, an atmospheric plasma discharge was employed to enhance the adhesion strength of joints between common beech (Fagus sylvatica L.) wood, metals (steel and aluminum alloy), and four different types of adhesives. The optical properties of plasma discharges and its influence on treated substrates' surface morphology depended on the inherent properties of the treated materials. X-ray photoelectron spectroscopy revealed the surface oxidation of all the materials after plasma treatment. Consequently, the surface free energy of all materials increased as well. The positive effect of the plasma treatment on
\end{abstract}

J. Žigon $(\bowtie) \cdot J$. Saražin $\cdot$ M. Šernek $\cdot$ M. Petrič · S. Dahle Department of Wood Science and Technology, Biotechnical Faculty, University of Ljubljana, Jamnikarjeva 101, 1000 Ljubljana, Slovenia e-mail: jure.zigon@bf.uni-lj.si

J. Kovač $\cdot$ R. Zaplotnik

Department of Surface Engineering and Optoelectronics, Jožef Stefan Institute, Jamova Cesta 39, 1000 Ljubljana, Slovenia the tensile shear strength of single-lap joints shows a high potential of atmospheric plasma treatment technology for enhancement of adhesives strength of joints combining wooden elements, wood and steel, or wood and aluminum alloys. In addition to that, expensive epoxy and polyurethane adhesives could be replaced by more affordable polyvinyl acetate and melamine-urea-formaldehyde adhesives, and still perform at equal levels if the plasma was applied prior to bonding.

Keywords Adhesives - Bonding · Metals · Wood · Plasma $\cdot$ Tensile shear strength $\cdot$ Surface

\section{Introduction}

Wood is one of the main renewable materials used for a huge number of end products such as pulp and paper, furniture, wooden frames, wooden panels, etc. (Pouzet et al. 2019). The interest in using wood in composites is ever increasing due to its lightweight, combustible, low-cost, and biodegradable properties. In recent years, continuous attention has been paid to the reinforced building structures made of wood-based materials (such as glulam beam, plywood and laminated veneer lumber) due to the excellent mechanical performance of wood, like good ratios between strength and density, its thermal insulation, renewability and durability (Tang et al. 2005; Zhang et al. 2019). The 
need for strengthening of wooden construction elements arises from different factors. One approach to improve the general bending responses is the reinforcement of outer surfaces with additional metal bars, nets or plates, made of steel or aluminum (Uzel et al. 2018). Composites made of wood and metals are interesting hybrid materials with the stiffness and strength of the metal being combined with the low density of wood-based materials. However, the adhesion at the interface between such lamination elements is often challenging (Jasieńko and Nowak 2014; Steiger et al. 2006). In order to connect such different materials, in the interface a wide range of different types of adhesives can be applied, acting as mediators, like for example phenol-resorcinol, epoxy and polyurethane adhesives (Tlustochowicz et al. 2011; Uzel et al. 2018). Still, the compatibility of these materials with adhesives used must be sufficient. The surface roughness, joints geometry and glue line thickness are important parameters that greatly affect the mechanical performance of the joint (Azinović et al. 2018; Budhe et al. 2015; Chans et al. 2013; Peng and Zhang 2018). The selection of an appropriate surface modification to increase the effectiveness of a joint depends on the material to be bonded and the bonding asset (Da Ponte et al. 2015; Williams et al. 2014).

Different mechanical, chemical and physical surface treatment methods can be applied since the created interaction forces depend on the substrate's surface morphology and surface chemistry (Nečasová et al. 2019; Sauerbier et al. 2018). Plasma treatment (PT) is a fast and versatile physical method for surface modification, which is environmentally friendly because of the absence of organic solvents (Lecoq et al. 2008). Nowadays it is well known in academia and industry and it is frequently used for surface engineering with a dedicated purpose. Plasma mainly consists of ions, electrons, neutrals, metastables, radicals and UV radiation, which is helpful for the activation or remarkable improvement of the surface wettability of different materials (Hippler 2001; Wagner et al. 2003). The effects of surface reactions with such particles are limited to a depth of several $100 \AA$ (Joshi and Butola 2013; Peng and Zhang 2018), whereas the bulk properties of the treated substrate remain unchanged (Chu et al. 2002; Recek 2019). In the case of wood, the effect is relatively stable in time, even a few days after modification (Talviste et al. 2019).

One of the atmospheric PT techniques is the configuration as dielectric barrier discharge (DBD). The term DBD refers to a kind of gas discharge in which the plasma is ignited between two electrodes, which are separated by a dielectric barrier (Brandt et al. 2016). It can be used for the fine cleaning and activation of surfaces and for enabling strong adhesion between wood or metal substrate and different polymers (Bour et al. 2008; Lahmar et al. 1995; Tang et al. 2005, 2006; Zhang et al. 2019, 2020). Treatment of wood and metals with such atmospheric plasma causes oxidation, generation and introduction of new oxygen-containing groups $(\mathrm{C}-\mathrm{O}, \mathrm{C}=\mathrm{O},(\mathrm{C}=\mathrm{O})-\mathrm{O}$ and $-\mathrm{OH})$ on the surface, while the presence of $\mathrm{C}-\mathrm{C}$ bonds decreases (Gramlich et al. 2006; Nguyen et al. 2016; Tang et al. 2005, 2006). This significantly increases the proportion of the polar component of surface free energy (SFE) and, therefore, decisively contributes to the hydrophilicity improvement of the surface (Sauerbier et al. 2018).

Metals have been exposed to non-thermal plasmas in various applications; but particularly steel is the favorite electrode material in DBD ozone generators (Kogelschatz 2000). DBD air plasmas were proven to effectively remove oil and to clean iron (Baravian et al. 1999) and aluminium surfaces (Klingner et al. 2013). Surface activation and advanced functionalities, however, are more commonly produced using Argon, Helium, or forming gas mixtures for metal surface activation (Goossens et al. 2001). Plasma pre-treated metal products have applications in the field of automobile, printed circuit board manufacturing, and electromagnetic interference, shielding materials, etc. (Kim et al. 2003). For example, the presence of these highly reactive species improves the pull-off strength of silicone rubber coating from steel (Latifi et al. 2014). Adhesion between steel and polyurethane, containing isocyanate groups, or with poly(pyromelliticdianhydride-co-4,4 V-oxydianiline) amic acid based adhesive, is enhanced due to the formation of $\mathrm{OH}$ groups on the steel surface after PT (Gähde et al. 1992; Tang et al. 2006). Carboxylic acids $(-\mathrm{COOH})$, formed on the steel surface promote strong chemical bonding to the epoxy film adhesive (Lee et al. 2009; Williams et al. 2014). The pretreatment of aluminum to enhance adhesion has been the subject of a very large amount of research (Critchlow 
and Brewis 1996). Aluminum exposed to the atmosphere at room temperature naturally forms a $2-3 \mathrm{~nm}$ thick oxide layer making it resistant to corrosion in the atmosphere ( $\mathrm{Li}$ and Wang 2009). PT is efficient in improving the adhesion of the polyurethane coating to the aluminum alloy (Mui et al. 2017).

Application of DBD plasmas to wood is much more challenging than to conventional substrates, due to the non-homogenous nature of this natural polymer (Levasseur et al. 2014). Therefore, proper treatment parameters need to be found (Peng and Zhang 2019; Talviste et al. 2019; Tang et al. 2006).

In the present research, the use of an atmospheric DBD plasma is studied as a surface preparation technique enhancing the bonding strength in the wood-metal hybrid composites. Its application to the surface of the wood and two metals is studied in detail to enhance the surfaces' compatibility. This is a novel approach to increase the adhesion between metal and wood, and thus achieve durable adhesive bonds.

Different materials systems are compared in terms of plasma physics using optical emission spectroscopy. Topographical changes caused by PT were studied with a confocal laser scanning microscope, whereas the elemental composition and the present functional groups on the substrates before and after PT were identified by X-ray photoelectron spectroscopy. The performance of the treated surfaces was analyzed through evaluation of surface free energies and measurements of tensile shear strengths with four different types of adhesives.

\section{Experimental}

Materials

The common beech (Fagus sylvatica, L.) samples were collected from sapwood part of boards with even proportion of early- and latewood of the dimensions $(100 \times 20 \times 3) \mathrm{mm}$, with a semi-radial orientation of the wood fibers. Two kinds of metals in the form of lamellae, with dimensions $(100 \times 20 \times 3) \mathrm{mm}$, were selected for this study: Aluminum (aluminum alloy grade 6063, 2678 $\pm 1 \mathrm{~kg} \mathrm{~m}^{-3}$ ) and steel (grade $235,7653 \pm 2 \mathrm{~kg} \mathrm{~m}^{-3}$ ). The densities of the metals were determined gravimetrically. All the specimens were stored in a chamber with a temperature of $20{ }^{\circ} \mathrm{C}$ and relative humidity (RH) of $65 \%$, where the wood samples reached a normal density of $708 \pm 2 \mathrm{~kg} \mathrm{~m}^{-3}$ and equilibrium moisture content of $10.8 \%$, as determined gravimetrically.

Plasma treatment process of the specimens

A floating-electrode DBD (FE-DBD) non-thermal plasma device (Žigon et al. 2019) was used to treat the surfaces of samples denoted "PT" in air at atmospheric pressure. The setup is schematically shown in Fig. 1. The parameters of an alternating high voltage (frequency $5 \mathrm{kHz}, 15 \mathrm{kV}$ peak voltage, peak current up to $90 \mathrm{~A}$ ) were regulated via a high voltage-power supply. Plasma was ignited between the surface of the treated work piece (moving rate $2 \mathrm{~mm} \mathrm{~s}^{-1}$ ) and two tubular ceramic hoses $\left(\mathrm{Al}_{2} \mathrm{O}_{3}\right.$, thickness $\left.2.5 \mathrm{~mm}\right)$ each with a round brass electrode (diameter of $15 \mathrm{~mm}$ ) inside. The distance between the dielectrics was set to $5 \mathrm{~mm}$, and the distance between the dielectrics and the surface of the workpiece was $1 \mathrm{~mm}$. The PT process was performed at the temperature of $20^{\circ} \mathrm{C}$ and RH $50 \%$.

\section{Optical discharge diagnosis}

The plasma discharges are composed of excited species (molecules, atoms and ions), which are important for plasma surface modification (Brandt et al. 2016; Hou and Jones 2000; Machala et al. 2007; $\mathrm{Yu}$ et al. 2008). Due to relaxation processes, these species lead to the emission of photons with characteristic wavelengths. The DBD plasma used in this study was analyzed via optical emission spectroscopy (OES) to identify the densities and the temperatures of the discharge species (Kim et al.

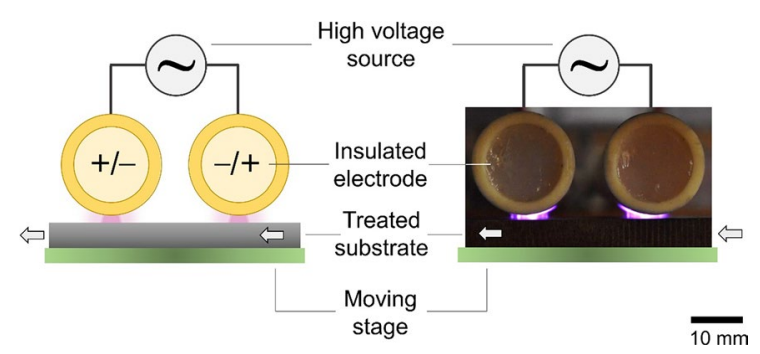

Fig. 1 Schematic presentation (left) and a photo (right) of FEDBD plasma in operation during treatment of a steel substrate. The photo of the discharge was taken by Nikon D5600 photo camera (f/7.1, 0.77 s, ISO 3200) 
2003; Prégent et al. 2015). Emission spectra of the formed plasma discharges were measured using a 16-bit Avantes AvaSpec-3648 (Avantes BV, Apeldoorn, the Netherlands) optical spectrometer with a 3648-pixel CCD detector array and $75 \mathrm{~mm}$ focal length. The optical lens was placed $1 \mathrm{~cm}$ from the generated discharge. The optical emission spectra were recorded with an integration time of $5 \mathrm{~s}$ and a resolution of $0.5 \mathrm{~nm}$ in the spectral range from 200 to $1100 \mathrm{~nm}$. Spectral sensitivity correction was not performed on the presented spectra.

Reduced electric fields have been evaluated from the nitrogen emission lines $\mathrm{N}_{2}^{+}\left(\mathrm{B}^{2} \Sigma_{\mathrm{u}}^{+} \rightarrow \mathrm{X}^{2} \Sigma_{\mathrm{g}}^{+}\right.$, $(0,0))$ at $391.4 \mathrm{~nm}$ and $\mathrm{N}_{2}\left(\mathrm{C}^{3} \Pi_{\mathrm{u}} \rightarrow \mathrm{B}^{3} \Pi_{\mathrm{g}},(2,5)\right)$ at $394.3 \mathrm{~nm}$ after Paris and colleagues (Paris et al. 2005, 2006; Pancheshnyi 2006; Kuchenbecker et al. 2009). Electron energies were calculated based on the reduced electric fields using the Bolsig + software version 03/2016 (Hagelaar and Pitchford 2005) with cross sections from the LXcat database (Pitchford 2013). The DBD discharges in this study do not fulfil the steady-state conditions for the equations as formulated by Paris et al. (2005). However, Bonaventura et al. (2011) proved that the equations are suited for determining accurate peak electric fields, and hence accurate peak values for average electron energies, as long as a sufficiently spatial and time-integrated optical emission spectrum is used.

\section{Surface roughness measurements}

In order to investigate the differences between the materials' topographies and the possible influence of PT on this parameter, surface roughness was studied. Morphological analysis of 5 samples' surfaces was performed with a confocal laser scanning microscope (CLSM) LEXT OLS5000 (Olympus, Tokyo, Japan). Each time, before and after PT, the same area of the individual sample was observed with a laser light source with a wavelength of $405 \mathrm{~nm}$ at a maximum lateral resolution of $0.12 \mu \mathrm{m}$. The topographical images of the area were taken at 10 - fold magnification (scanned area of about $1280 \mu^{2}$ ) and the software OLS50-S-AA (Olympus, Tokyo, Japan) was used to calculate the areal roughness parameter $\mathrm{Sa}$ (arithmetic mean of the deviations from the mean samples surface).
X-ray photoelectron spectroscopy (XPS)

XPS measurements were carried out to identify the chemical composition and different chemical species on surfaces of samples before and after PT. XPS analyses were performed on 2 different spots on the samples of $(10 \times 10) \mathrm{mm}^{2}$ in size using a TFA-XPS spectrometer (Physical Electronics, Inc. Chanhassen, Minnesota, USA). The spectra were acquired at a base pressure of $10^{-9}$ mbar using a focused monochromatic $\mathrm{Al} \mathrm{K}_{\alpha}$ source (photon energy $1486.68 \mathrm{eV}$, power $200 \mathrm{~W}$ ), from an area of $400 \mu \mathrm{m}$ in diameter. Excited photoelectrons were emitted at $45^{\circ}$ to the samples' surfaces normals. Typical information depths of the XPS method are in the range of 3-5 $\mathrm{nm}$. Data elaboration, including spectral calibration, processing, fitting routines, and atomic concentration calculations, was performed using the XPS database and the Multipak v.8.1 software. The measured photoelectron spectra were decomposed using a Gauss-Lorentz peak shape. The oxide layer thickness of aluminum samples was calculated after Ertl and Küppers (1985) and Strohmeier (1990) using inelastic mean free paths from the NIST database 71 v1.2 (Powell and Jablonski 2010) with the dataset of Tanuma, Powell, and Penn for aluminum metal and the dataset after Ackermann et al. for $\mathrm{Al}_{2} \mathrm{O}_{3}$.

Contact angle (CA) measurements and calculation of surface free energy (SFE)

The surface wetting analysis was done by CA measurements of deionized water, diiodomethane and formamide, by the Young-Laplace analysis. Before starting the measurements, the analyzed spots of the substrates were sanded by sanding paper grid P240. CA measurements, used to calculate SFE are affected by many factors, e.g., surface roughness, material composition, surface crystallinity, and surface charge (Kaelble 1970). Optical goniometer Theta (Biolin Scientific Oy, Espoo, Finland), and the corresponding software (OneAttension version 2.4 [r4931], Biolin Scientific, Oy, Espoo, Finland) were used to measure the CA between the substrate's surface and the tangent fitting to the shape of $3 \mu \mathrm{L}$ droplet on its both sides. From these data, SFE was calculated using the Owens-Wendt method (Owens and Wendt 1969). 
Bonding and tensile shear strength testing of the specimens

Finally, the quality of the adhesive bonds was evaluated by a tensile shear strength test of specimens with single-lap joints (Fig. 2). The bonding spots $(20 \times 10) \mathrm{mm}$ of the lamellas were sanded with a sanding paper of the grid P120 and cleaned with 98\% acetone to remove contaminants from the surface prior to bonding. Four types of adhesives were used: (1) 2-component melamine-urea-formaldehyde Prefere (MUF, Dynea AS, Lillestrøm, Norway), (2) polyvinyl acetate Mekol D2 (PVAc, Mekol d.o.o., Sežana, Slovenia), (3) 2-component epoxy (epoxy, UHU, Bühl, Germany), and (4) 1-component polyurethane Mitopur E45 (PU, Mekol d.o.o., Sežana, Slovenia). Among the selected adhesives, the solution 1 and the dispersion 2 are aqueous formulations, whereas 3 and 4 are waterless resins. Each particular adhesive was applied to the bonding area $\left(200 \pm 10 \mathrm{~g} \mathrm{~m}^{-2}\right)$ and spread over it using a spatula. The specimens were bonded by applying constant pressure (1 MPa) on specimens for $24 \mathrm{~h}$ at room temperature. The tensile shear strength testing was performed according to EN 205 (2016) standard. Ten specimens per series were tested with a universal testing machine (Z005, ZwickRoell, Ulm, Germany), with a constant movement of testing jaws of $2 \mathrm{~mm} \mathrm{~min}^{-1}$. After the end of the test, the percentage of wood failure was estimated visually.

\section{Results}

\section{Optical emission spectra}

Figure 3 shows the OES spectra and photos of the discharges, recoded during the treatment of beech wood, steel and aluminum substrate with the FE-DBD atmospheric plasma. As a typical plasma

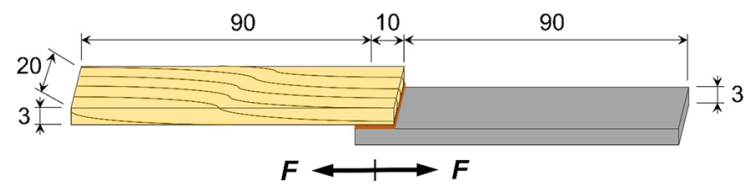

Fig. 2 Schematic presentation of a single-lap joint specimen for the determination of tensile shear strength of adhesive bond, consisting of wooden and metal lamellae

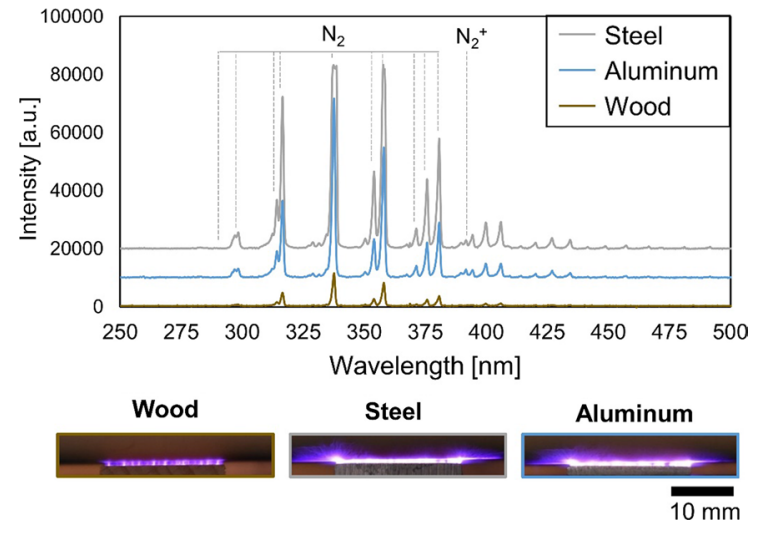

Fig. 3 Recorded OES spectra and photographs of atmospheric plasma discharge during treatment of different substrates with FE-DBD plasma (integration time $5000 \mathrm{~ms}$ ). The photos of the discharges on wood, steel and aluminum were taken by Nikon D5600 photo camera (f/7.1, $0.77 \mathrm{~s}$, ISO 3200)

discharge in atmospheric air (Belmonte et al. 2015; Laux et al. 2003; Šantak et al. 2015), the most intense second positive system of $\mathrm{N}_{2}$ emission lines between 290 and $450 \mathrm{~nm}(316 \mathrm{~nm}, 337 \mathrm{~nm}, 357 \mathrm{~nm}, 376 \mathrm{~nm}$, $381 \mathrm{~nm}$ ) and the $\mathrm{N}_{2}{ }^{+}$emission line at $391 \mathrm{~nm}$ were visible. No additional spectral features were found at given acquisition parameters when treating different materials, whereas the intensity of the measured emitted light differed greatly. The lowest intensity was detected when treating beech wood, more intense at the treatment of aluminum (about 8 times higher than at wood) and steel (about 15 times higher than at wood). The results of reduced field strengths and electron energy analysis are shown in Table 1.

Surfaces' morphologies

From Fig. 4 it can be observed that wood had the highest surface roughness in comparison with both metals. Aluminum expressed higher values of roughness arithmetic mean height than steel, which could be related to lower density and yielding by sanding of aluminum, in comparison to steel with higher density. PT increased the surface roughness of steel $(6.4 \%)$ approx. in the order of magnitude of the standard deviation, whereas no change was detectable for neither aluminum nor wood. Surface etching appeared was more pronounced when treating steel with plasma, which could be related to the more intense light emission during PT detected by OES, and 
Table 1 Calculated reduced field strengths and electron energy analysis

\begin{tabular}{llc}
\hline Treated material & Reduced field strength $(\mathrm{E} / \mathrm{N})(\mathrm{Td})$ & Electron energy $(\mathrm{eV})$ \\
\hline Wood & 342 & 4.9 \\
Steel & 505 & 6.6 \\
Aluminum & 659 & 7.8 \\
\hline
\end{tabular}

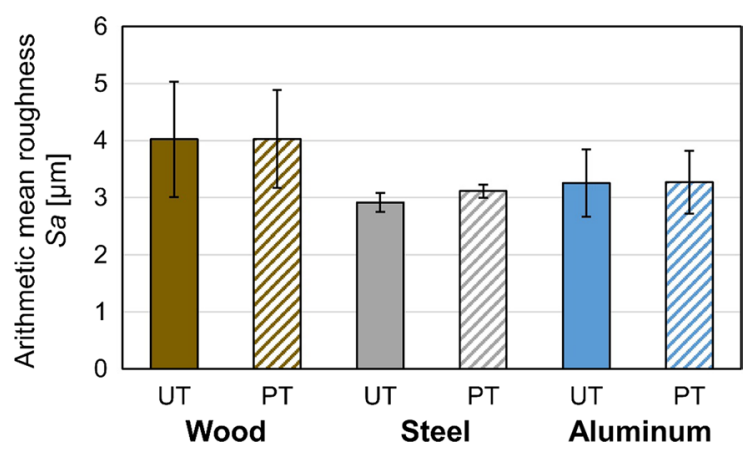

Fig. 4 Arithmetic mean roughness of wood, steel and aluminum samples surface before (UT) and after PT

oxidation with the formation of oxide nodules appearing on the surface (c.f. fig. S1). The detected surface topography pictures of steel surface before and after treatment with plasma are given in the article's complete dataset (Žigon et al. 2020).

\section{XPS spectra}

Representative XPS spectra are presented in Fig. 5. They revealed a significant change in surface chemistries of beech wood, steel and aluminum surfaces after PT. The chemical composition of the surface layer analyzed by XPS method is given in Tab. S1 in the supplementary information (Žigon et al. 2020).

On beech wood, high-energy resolution $\mathrm{C} 1 \mathrm{~s}$ spectra acquired were decomposed into three components at the following bonding energies: $\mathrm{C}_{1}$ (at $284.5 \mathrm{eV}$ ), $\mathrm{C}_{2}$ (at $286.6 \mathrm{eV}$ ), and $\mathrm{C}_{3}$ (at $288.9 \mathrm{eV}$ ) representing aliphatic $(\mathrm{C}-\mathrm{C}, \mathrm{C}-\mathrm{H})$, hydroxyl $(\mathrm{C}-\mathrm{O})$, and carbonyl $(\mathrm{C}=\mathrm{O}, \mathrm{O}-\mathrm{C}-\mathrm{O})$ groups, respectively (Fig. 5a). In contrast to other cases of plasma-treated wood surfaces, no notable amounts of carboxy groups $(\mathrm{O}-\mathrm{C}=\mathrm{O})$ were present in these results. An air plasma treatment of the wood surface resulted in an increase of the $\mathrm{O} / \mathrm{C}$ ratio from initially $0.52-0.82$ after treatment. The increase in oxygen containing groups is in agreement with similar XPS studies performed on wood (Avramidis et al. 2012; Tóth et al. 2007) and with similar studies showing an increased polar part of the SFE (Král et al. 2015). The most significant changes on the surface of beech wood resulting from PT are a strong decrease of $\mathrm{C}_{1}(\mathrm{C}-\mathrm{C}, \mathrm{C}-\mathrm{H})$ component (by $18.7 \%$ ), an increase of $\mathrm{C}_{2}(\mathrm{C}-\mathrm{O})$ component (by 5.3\%), and a strong increase of $\mathrm{C}_{3}(\mathrm{C}=\mathrm{O}, \mathrm{O}-\mathrm{C}-\mathrm{O})$ component (by 13.4\%) (Gerullis et al. 2018; Peng and Zhang 2018; Talviste et al. 2019). Thereby, the $\mathrm{C}_{2}$ component mainly originates in the $\mathrm{C}-\mathrm{O}$ bonds within cellulose, because of its high stability and high resistance to PT (Klarhöfer et al. 2010). Further, this is in good accordance with the removal of volatile organic compounds and resins from the wood surface, which was proven by earlier studies (Avramidis et al. 2012). The $\mathrm{O}$ 1s spectra before and after PT at 533.3 and $533.0 \mathrm{eV}$, respectively, show an increase in intensity after PT, corresponding well to the oxidation of the wood surface with PT indicated by the $\mathrm{C} 1 \mathrm{~s}$ spectra (Fras et al. 2005).

Detected changes in the chemical composition of steel after PT are presented in XPS spectra given in Fig. 5b. The analyses of $\mathrm{Fe} 2 \mathrm{p}$ spectra reveal mostly an increase of the $\mathrm{FeOOH}$ peak (by $9.5 \%$, at $713.7 \mathrm{eV}$ ) while the $\mathrm{Fe}_{2} \mathrm{O}_{3}$ peak and its satellite decreased by $11.1 \%$ at $711.0 \mathrm{eV}$ and by $8.5 \%$, at $720.0 \mathrm{eV}$, respectively. The corresponding $\mathrm{O} 1 \mathrm{~s} \mathrm{spec-}$ tra show an increase of Fe-oxide by $3.2 \%$ at $533.7 \mathrm{eV}$, a decrease of $\mathrm{OH}$ and $\mathrm{H}_{2} \mathrm{O}$ by $0.4 \%$ at $531.7 \mathrm{eV}$, and a decrease of $\mathrm{Fe}_{2} \mathrm{O}_{3}$ and $\mathrm{CO}$ by $2.9 \%$ at $530.0 \mathrm{eV}$. This supports the generation of new oxides out of complex surface compounds indicated by the Fe $2 p$ spectra. This is accompanied by a small decrease of the $\mathrm{O} / \mathrm{Fe}$ ratio from initially 5.67-5.40 after PT (Tang et al. 2006; Volgmann et al. 2010). Further, the PT reduced the carbon content at the surface (c.f. Fig. S2 in supplements as well as Žigon et al. 2020), which is mostly related to adsorbed atmospheric contaminants.

Figure $5 \mathrm{c}$ shows the $\mathrm{Al} 2 \mathrm{p}$ and $\mathrm{O} 1 \mathrm{~s}$ spectra of aluminum samples. Aluminum atoms react with oxygen 
Wood
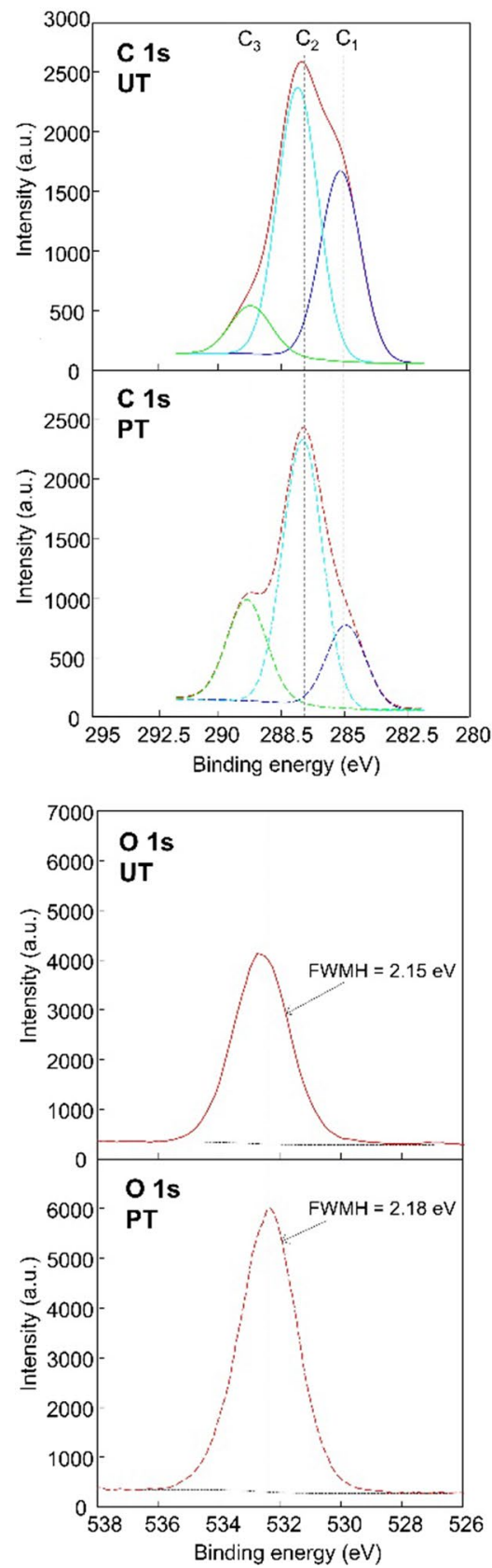

Steel
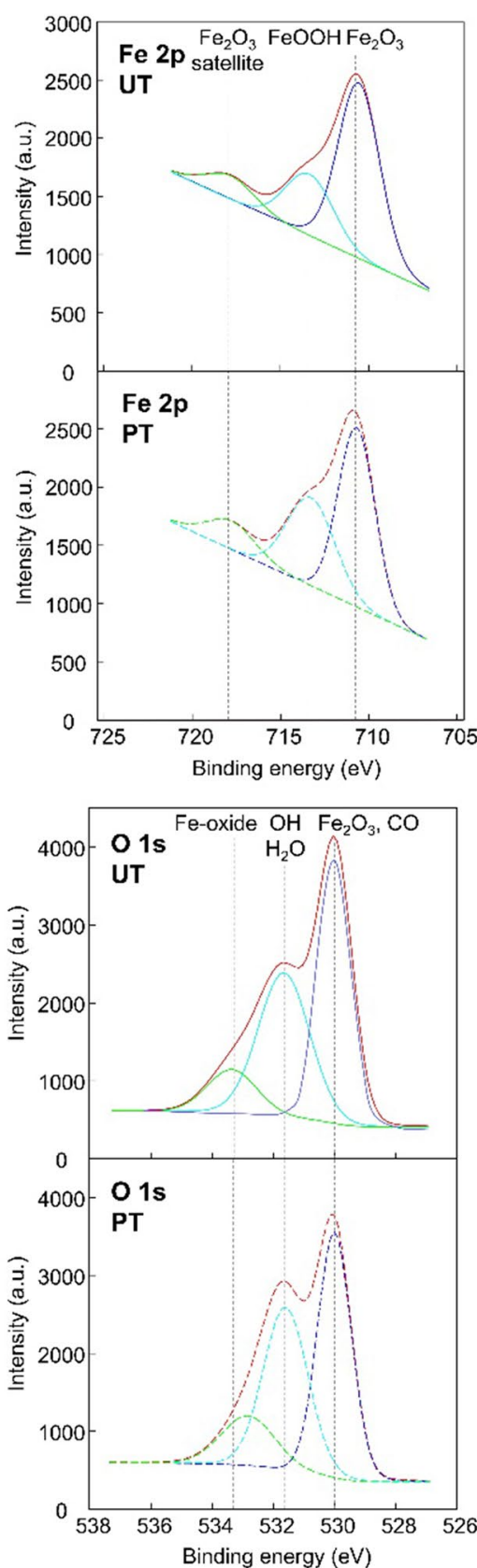

Aluminum
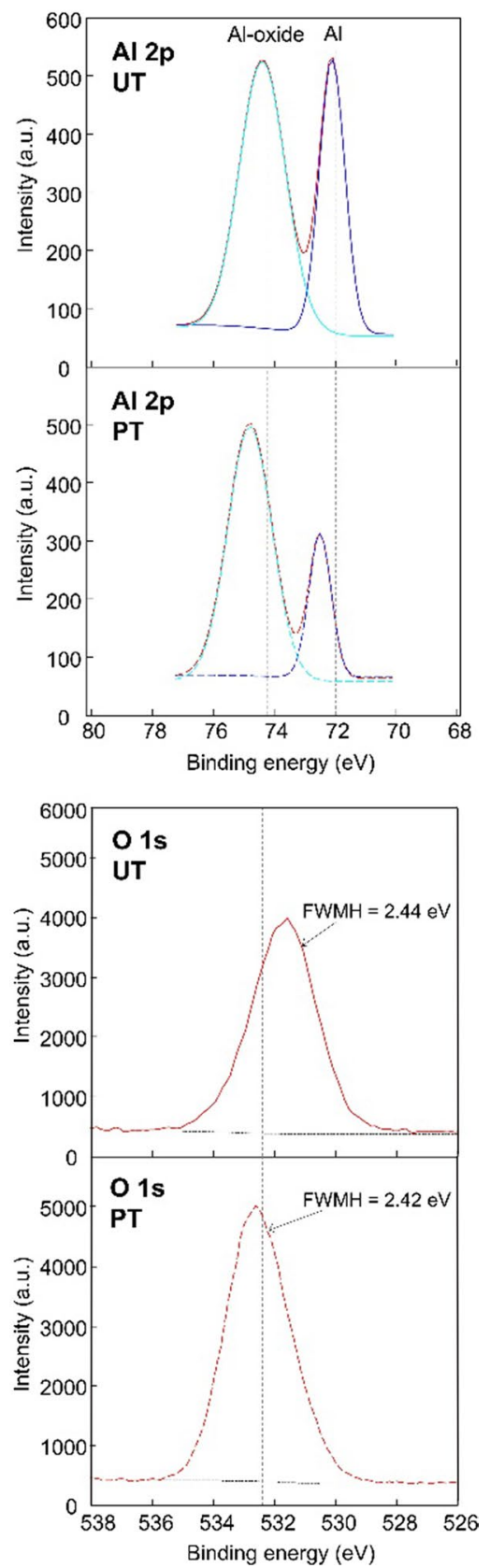

Fig. 5 High-energy resolution XPS spectra of beech wood, steel, and aluminum. The filled lines represent the spectra peaks detected at untreated (UT) samples while the dashed lines represent the spectra peaks in case of plasma treated (PT) samples

to form aluminum oxides mostly within the thermodynamic stable form $\mathrm{Al}_{2} \mathrm{O}_{3}$. The low binding energy $\mathrm{Al} 2 \mathrm{p}$ peak at $72.6 \mathrm{eV}$ is attributed to metallic aluminum, which decreased in intensity for $50 \%$ after PT. The peak at $74.2 \mathrm{eV}$ indicates $\mathrm{Al}_{2} \mathrm{O}_{3}$ formed on the surface, slightly increasing after PT. The O $1 \mathrm{~s}$ spectra with the intense peak at a binding energy of $532.2 \mathrm{eV}$, is associated with the presence of oxygen in the form of $\mathrm{Al}_{2} \mathrm{O}_{3}$, which intensity increased after PT. There is a slight shift of $\mathrm{Al} 2 \mathrm{p}$ and $\mathrm{O}$ 1s peaks on the 
binding energy scale from aluminum samples after PT probably related to thicker Al-oxide and charging effect due to the dielectric nature of this oxide layer. We calculated thicknesses of the aluminum-oxide layers, and found an increase from initially $2.2-3.2 \mathrm{~nm}$ after PT. The O/Al ratio increased from 2.1 to 3.4 , which confirms the surface oxidation of aluminum by formation of a thicker layer of $\mathrm{Al}_{2} \mathrm{O}_{3}$ after PT (Klingner et al. 2013). Furthermore, a significant fraction of nitrate species (5.2\%) was detected on the surface after PT, as evidenced by the $\mathrm{N} 1 \mathrm{~s}$ peak at $407.5 \mathrm{eV}$ (c.f. Fig. S3 in supplements as well as Žigon et al. 2020).

All XPS analysis data are summarized in the supplements, Table S1.

\section{Surface free energy}

After PT, the total SFE of all materials surfaces increased as shown in Fig. 6. The increase of the polar components is in agreement with the literature, where the surfaces of beech wood (Král et al. 2015; Wascher et al. 2015; Wolkenhauer et al. 2009), steel (Latifi et al. 2014; Lee et al. 2009; Lin and Chang 2011) and aluminum (Kim et al. 2003; Mui et al. 2017) were activated by plasma. The increment of total SFE, both relative in comparison to surfaces in untreated state and in absolute numbers, was the highest for steel (76.5\%), followed by beech wood (15.4\%) and aluminum (6.0\%). The increment of its

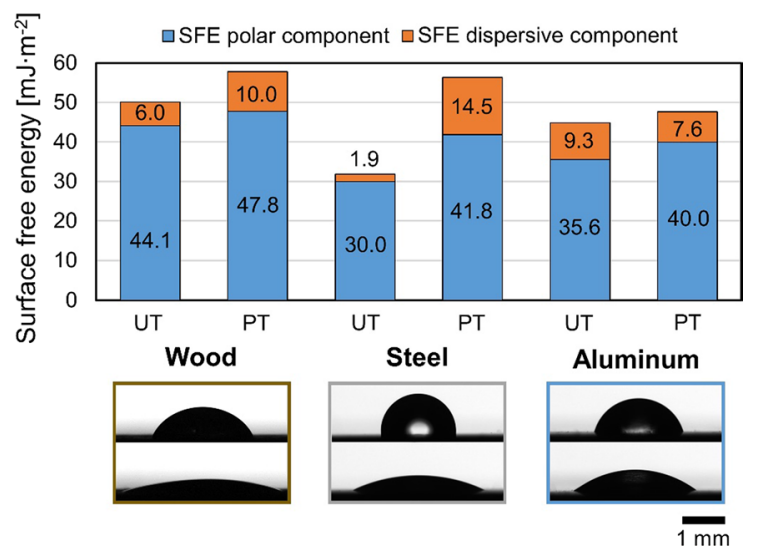

Fig. 6 Calculated polar and dispersive part of total SFE for different untreated (UT) and PT materials' surfaces. Photographs of water droplets taken $1 \mathrm{~s}$ after application, applied on wood, steel and aluminum are shown below the chart: UT samples (above), PT samples (below) polar component was the highest at steel, aluminum and beech wood. It is notable that the dispersive part of the SFE increased after the plasma activation by $2 / 3$ on wood and by a factor of 7.6 on steel, but it decreased by $1 / 5$ on aluminum. This is likely a combined effect of the surfaces' morphologies and chemical composition. The removal of contaminants and extractives especially on aluminum and wood is due to the mechanical effect of the bombardment by the plasma ions on the surface and to the chemical interaction of the charged particles with the contaminants, as for instance reported by Bónová et al. (2015), Polini and Sorentino (2003) for aluminum, or Avramidis et al. (2012) for wood. In addition, treatment caused the generation of corrosive structures on steel (Kiyokawa et al. 1999; Tang et al. 2005; Rodríguez-Villanueva et al. 2013; Williams et al. 2017), and in general the polar surface states through oxidation (Thomas and Mittal 2013) on all three substrates.

Tensile shear strength of lap joints

The measured tensile shear strengths, in dependence of the bonded substrate and used adhesive type are shown in Fig. 7. The results clearly show strongly improved tensile shear strength of single-lap joints between wood, wood and steel, and wood and aluminum after PT, especially when aqueous adhesives (PVAc dispersions and MUF solutions) were used.

Single-lap joints composed of two beech wood lamellas and bonded with different adhesives (Fig. 7a), expressed the highest tensile shear strength values among all types of specimens used in this study. The changes in tensile shear strength induced by PT all stayed within the standard deviation for wood-wood bonds. In comparison to untreated substrates, tensile shear strength values for PT samples increased for joints bonded with PVAc (by 10.8\%) and MUF (by $11.8 \%$ ), while the PT did not contribute to strength improvement at PU and epoxy adhesives. The joints bonded with the epoxide adhesive showed the highest strength values accompanied with failure in wood, meaning that the adhesion of the adhesive was higher than the internal bonding strength of wood (cohesive failure of the wood substrate was observed).

The joints between PT beech wood and PT steel bonded with water-based adhesive yielded higher 
(a)

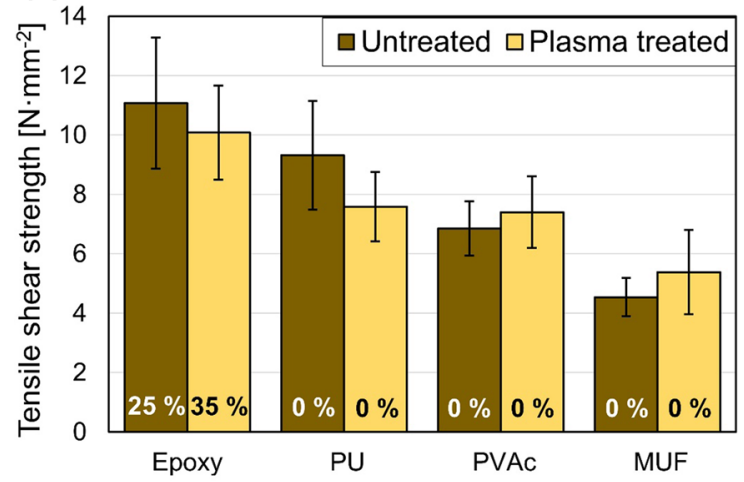

(b)

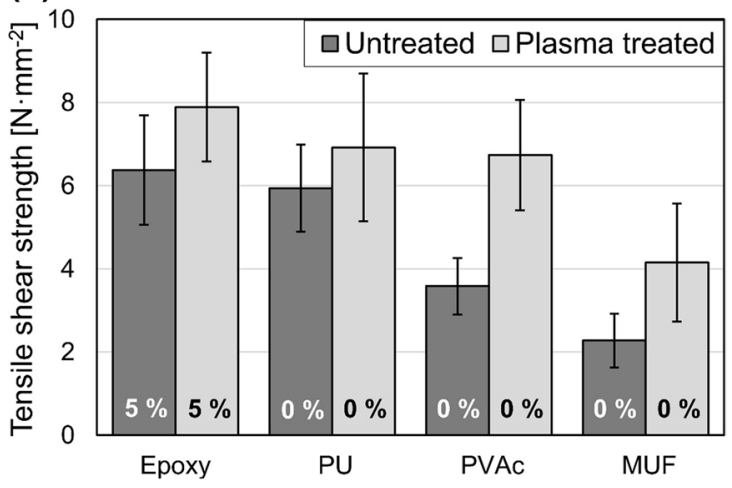

(c)

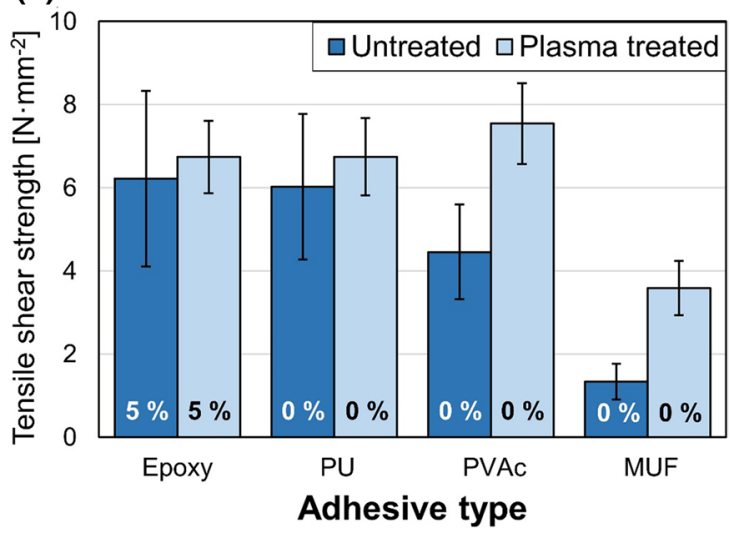

Fig. 7 Tensile shear strength of single-lap joints specimens: wood-wood (a), wood-steel (b) and wood-aluminum (c), in dependence of substrate preparation (untreated or PT). The percentage of wood failure is stated at the bottom of particular column corresponding to adhesive type

tensile shear strengths (PVAc by $88.7 \%$ and MUF by $82.8 \%)$ than the respective untreated ones. The increment for epoxy was lower (by 23.9\%) and just barely exceeded the standard deviation of the measured data point. No influence of PT on tensile shear strength of PU adhesives was evident. However, the strength of joints created with PVAc after PT reached the level of bond strength of PU and epoxy (Fig. 7b).

The highest values of joints tensile shear strength between untreated beech wood and aluminum were found for PU and epoxide adhesives, where PT again did not show any significant effect, as shown in Fig. 7c. In contrast to that, PT increased the joints' tensile shear strengths for PVAc (by 69.5\%) and MUF (by $65.0 \%$ ).

The dataset of detected elongations at the maximum load of the tensile shear strength of lap joints was provided by Žigon et al. (2020).

\section{Discussion}

In general, plasmas are known to primarily influence the outermost surfaces through chemical modification of the material, which then builds the interface layer upon bonding. These modifications can be checked particularly well through measurements of contact angles and surface free energies. Hence, the bonding properties of the formed joints with different adhesives are usually well correlated to wetting properties. Adhered surfaces, oxidized and polarized by PT, interact differently with adhesive molecules of different adhesives. Specifically, polar surface groups on PT materials contribute to the formation of additional hydrogen at the interface between oxygen-containing adhesives (PVAc and MUF) and PT substrates (Avramidis et al. 2011; Frihart 2005).

\section{PT for wood-wood joints}

Initially, the surface of the wood was relatively rough, which did not change significantly with plasma treatments. The outermost surface of wood clearly gets oxidized through the removal of volatile compounds and resins as well as the formation of hydroxyl, carbonyl, and carboxyl groups, which is clearly represented by the increase of both, polar and dispersive parts of the SFE after PT (Liu and Rials 1998; Shen 2009). Hence, the bond strengths of aqueous adhesive systems, i.e. PVAc and MUF adhesives, seemed to slightly increase, whereas they appeared to slightly decrease for epoxy and PU adhesives. However, none of these changes was statistically significant, 
although yielding the highest tensile shear strength values among all the types of specimens bonded with different adhesives used in this study. The strengths of bondlines between two beech lamellas were the highest in comparison to strengths, detected at wood and both studied metals. This could be attributed to the basic purpose of adhesives used and to the adhesives' penetration, which is expected to be greater for more porous materials like wood than for non-porous metals.

\section{PT for wood-steel joints}

The slightly increased surface roughness of steel after PT was a consequence of surface etching and intense generation of new oxides, as detected with XPS. In particular, the formation of a plasma induced oxide layer coincided with an increase of iron(III) oxide hydroxide and a decrease of stoichiometric iron(III) oxide and carbon containing compounds. The formation of the oxide layer was thus accompanied by a slight decrease of the $\mathrm{O} / \mathrm{Fe}$ ratio. The more intense light emission during PT detected by OES relates to amount of discharge energy transmitted to the treated substrate (O'Connor et al. 2003; Stancu et al. 2010), whereas the mean electron energies were smaller than those at the aluminum substrates. This might be caused by the oxide layer leading to an enhancement during the breakdown phase of the plasma. In this study, the increase of SFE after PT was the most pronounced by far on steel substrates for both, the polar and the dispersive part. This highly contributed to the enhancement of the tensile shear strength at wood-steel joints, created with water-based adhesives, particularly in the case of PVAc the level reached the one created with epoxy and PU. Here, we can conclude that the increased polar character and increased roughness of substrates, created with PT, are the reasons for better interaction of these with water-based adhesives, contributing to higher strengths of joints. Furthermore, the slight increase of surface roughness due to the formation of the oxide layer might play a role in enhancing the bond strengths through effects of mechanical firm closure.

\section{PT for wood-aluminum joints}

Similar to steel, aluminum showed a promotion of oxidation of the surfaces after PT and beside this, higher initial surface roughness. Since neither the nature of the surface oxide nor the surface roughness did change significantly, the SFE showed rather a slight decrease of the dispersive part. The polar part of the SFE, however, slightly increased, which might be promoted by the nitrate groups that formed at a proportion of approx. 5\% at the PT aluminum surface (Prysiazhnyi et al. 2012; Bónová et al. 2015). Accordingly, the bond strengths of the aqueous adhesives PVAc and MUF increased significantly, whereas epoxy and PU did only show insignificant changes. Nevertheless, the highest values of joints' tensile shear strengths between untreated beech wood and aluminum were found for PU and epoxy adhesives.

\section{Conclusions}

During the treatments of wood, steel and aluminum with FE-DBD plasma discharge in air at atmospheric pressure, only $\mathrm{N}_{2}$ and $\mathrm{N}_{2}^{+}$emissions were identified with optical emission spectroscopy, which is typical for these kinds of plasmas. However, the emitted light was found to be related to the dielectric permittivity and electric conductivity of the substrates. Higher reduced electric field strength and higher electron energies indicate a larger number of gas species with higher excited states (Coburn and Chen 1980), and also higher energy transfer (by ratio of capacitance between the two electrodes and between electrodes and substrate) An increase of the surface roughness by PT was most pronounced on steel, which also relates to a higher intensity of the emitted light, whereas no changes were observed for aluminum and wood. The plasma treatments yielded the oxidation of all tested materials, which was presented in the form of polar groups on wood, an increase in oxide layer on aluminum, and a formation of a corrosion layer with oxide nodules on the steel surface. These XPS results were in good agreement with the calculated surface free energies (SFE). The polar part of SFE in comparison to untreated surfaces the most increased at steel (39.3\%), followed by aluminum (12.4\%) and wood $(8.3 \%)$. Finally, the positive effect of the PT on the tensile shear strength of single-lap joints was found, mostly when the water-based adhesive types (PVAc and MUF) were used.

These findings show the high potential of atmospheric PT technology for the enhancement of 
adhesive strength of joints between wood and metals (namely steel and aluminum). Moreover, this study proves that costly and less environmentally friendly epoxy and PU adhesives can be substituted with more affordable adhesives such as aqueous PVAc or MUF dispersions. The simple air plasma pretreatment ensures equally strong joints for the discussed metalwood combinations if applied before joining.

Acknowledgments The authors acknowledge the financial support from the Slovenian Research Agency (Research Programmes Funding No. P4-0015, "Wood and lignocellulose composites" and No. P2-0082, "Thin-film structures and plasma surface engineering"). This project has received funding from the European Union's Horizon 2020 research and innovation programme under grant agreement No. 745936. The help of Tatjana Filipič from Jožef Stefan Institute for XPS analysis is gratefully acknowledged.

Open Access This article is licensed under a Creative Commons Attribution 4.0 International License, which permits use, sharing, adaptation, distribution and reproduction in any medium or format, as long as you give appropriate credit to the original author(s) and the source, provide a link to the Creative Commons licence, and indicate if changes were made. The images or other third party material in this article are included in the article's Creative Commons licence, unless indicated otherwise in a credit line to the material. If material is not included in the article's Creative Commons licence and your intended use is not permitted by statutory regulation or exceeds the permitted use, you will need to obtain permission directly from the copyright holder. To view a copy of this licence, visit http://creativecommons.org/licenses/by/4.0/.

\section{References}

Avramidis G, Nothnick E, Militz H, Viöl W, Wolkenhauer A (2011) Accelerated curing of PVAc adhesive on plasmatreated wood veneers. Eur J Wood Prod 69:329-332. https://doi.org/10.1007/s00107-010-0429-7

Avramidis G, Klarhöfer L, Maus-Friedrichs W, Militz H, Viöl W (2012) Influence of air plasma treatment at atmospheric pressure on wood extractives. Polym Degrad Stab 97(3):469-471. https://doi.org/10.1016/j.polymdegra dstab.2011.12.030

Azinović B, Serrano E, Kramar M, Pazlar T (2018) Experimental investigation of the axial strength of glued-in rods in cross laminated timber. Mater Struct 51:143. https:// doi.org/10.1617/s11527-018-1268-y

Baravian G, Chaleix D, Nauche PL, Puech V, Rozoy M (1999) Oil removal from iron surfaces by atmospheric-pressure barrier discharges. Surf Coat Technol 115(1):66-69. https://doi.org/10.1016/S0257-8972(99)00162-0

Belmonte T, Noël C, Gries T, Martin J, Henrion G (2015) Theoretical background of optical emission spectroscopy for analysis of atmospheric pressure plasmas. Plasma Sources Sci Technol 24:29. https://doi.org/10.1088/0963-0252/ 24/6/064003

Bonaventura Z, Bourdon A, Celestin S, Pasko VP (2011) Electric field determination in streamer discharges in air at atmospheric pressure. Plasma Sources Sci Technol 20(3):035012. https://doi.org/10.1088/0963-0252/20/3/ 035012

Bónová L, Zahoranová A, Kováčik D, Zahoran M, Mičušík M, Černák M (2015) Atmospheric pressure plasma treatment of flat aluminum surface. Appl Surf Sci 331:79-86. https://doi.org/10.1016/j.apsusc.2015.01. 030

Bour J, Bardon J, Aubriet H, Del Frari D, Verheyde B, Dams R, Vangeneugden D, Ruch D (2008) Different ways to plasma-polymerize HMDSO in DBD configuration at atmospheric pressure for corrosion protection. Plasma Process Polym 5:788-796. https://doi.org/10.1002/ppap. 200800052

Brandt S, Schütz A, Klute DF, Kratzer J, Franzke J (2016) Dielectric barrier discharges applied for optical spectrometry. Spectrochim Acta Part B 123:6-32. https://doi.org/10. 1016/j.sab.2016.07.001

Bruggeman P, Iza F, Guns P, Lauwers D, Kong MG, Gonzalvo YA, Leys C, Schram DC (2010) Electronic quenching of $\mathrm{OH}(\mathrm{A})$ by water in atmospheric pressure plasmas and its influence on the gas temperature determination by $\mathrm{OH}(\mathrm{A}-$ X) emission. Plasma Sources Sci Technol 19:015016. https://doi.org/10.1088/0963-0252/19/1/015016

Budhe S, Gumatkar A, Birajdar N, Banea DM (2015) Effect of surface roughness using different adherend materials on the adhesive bond strength. Appl Adhes Sci 3(1):20. https://doi.org/10.1186/s40563-015-0050-4

Chans OD, Cimadevila EJ, Gutiérrez ME (2013) Withdrawal strength of threaded steel rods glued with epoxy in wood. Int J Adhes Adhes 44:115-121. https://doi.org/10.1016/j. ijadhadh.2013.02.008

Chu PK, Chen JY, Wang LP, Huang N (2002) Plasma-surface modification of biomaterials. Mater Sci Eng R Rep 36(5):143-206. https://doi.org/10.1016/S0927-796X(02) 00004-9

Coburn JW, Chen M (1980) Optical emission spectroscopy of reactive plasmas: a method for correlating emission intensities to reactive particle density. J Appl Phys 51(6):3134. https://doi.org/10.1063/1.328060

Critchlow WG, Brewis MD (1996) Review of surface pretreatments for aluminium alloys. Int $\mathbf{J}$ Adhes Adhes 16:255275. https://doi.org/10.1016/S0143-7496(96)00014-0

Da Ponte G, Ghosh KA, Kakaroglou A, Van Hemelrijck D, Van Mele B, Verheyde B (2015) Adhesion improvement between epoxy and stainless steel using a silane coupling agent in an atmospheric plasma process. Plasma Process Polym 12:347-361. https://doi.org/10.1002/ppap.20140 0106

EN 205 (2016) Adhesives-Wood adhesives for non-structural applications-Determination of tensile shear strength of lap joints. European Committee for Standardisation, Brussels, Belgium

Ertl G, Küppers J (1985) Low energy electrons and surface chemistry, 2nd edn. VCH Verlagsgesellschaft, Weinheim 
Fras L, Johansson L-S, Stenius P, Stana-Kleinschek K, Ribitsch V (2005) Analysis of the oxidation of cellulose fibres by titration and XPS. Colloids Surf A 260(1-3):101-108. https://doi.org/10.1016/j.colsurfa.2005.01.035

Frihart CR (2005) Wood adhesion and adhesives. In: Rowell RM (ed) Handbook of wood chemistry and wood composites, 2nd edn. CRC Press, Boca Raton, pp 255-319

Gähde J, Friedrich FJ, Gehrke R, Loeschcke I, Sachse J (1992) Adhesion of polyurethane to surface-modified steel. J Adhes Sci Technol 6(5):569-586. https://doi.org/10.1163/ 156856192 X00403

Gerullis S, Kretzschmar BS-M, Pfuch A, Beier O, Beyer M, Grünler B (2018) Influence of atmospheric pressure plasma jet and diffuse coplanar surface barrier discharge treatments on wood surface properties: a comparative study. Plasma Process Polym 15(10):1800058. https://doi. org/10.1002/ppap.201800058

Goossens O, Dekempeneer E, Vangeneugden D, Van de Leest R, Leys C (2001) Application of atmospheric pressure dielectric barrier discharges in deposition, cleaning and activation. Surf Coat Technol 142-144:474-481. https:// doi.org/10.1016/S0257-8972(01)01140-9

Gramlich MW, Gardner JD, Neivandt JD (2006) Surface treatments of wood-plastic composites (WPCs) to improve adhesion. J Adhes Sci Technol 20(16):1873-1887. https:// doi.org/10.1163/156856106779116623

Hagelaar GJM, Pitchford LC (2005) Solving the Boltzmann equation to obtain electron transport coefficients and rate coefficients for fluid models. Plasma Sources Sci Technol 14:722-733

Hippler R (2001) Low temperature plasma physics: fundamental aspects and applications, 1st edn. Wiley-VCH, Berlin

Hou X, Jones BT (2000) Inductively coupled plasma/Optical emission spectrometry. In: Meyers RA (ed) Encyclopedia of analytical chemistry. Wiley, Chichester, pp 9468-9485. https://doi.org/10.1002/9780470027318.a5110.pub3

Jasieńko J, Nowak PT (2014) Solid timber beams strengthened with steel plates-experimental studies. Constr Build Mater 63:81-88. https://doi.org/10.1016/j.conbuildmat. 2014.04.020

Joshi M, Butola BS (2013) Application technologies for coating, lamination and finishing of technical textiles. In: Gulrajani ML (ed) Advances in the dyeing and finishing of technical textiles. Woodhead Publishing Series in Textiles, New Delhi, pp 355-411

Kaelble DH (1970) Dispersion-polar surface tension properties of organic solids. J Adhes 2:66-81. https://doi.org/10. 1080/0021846708544582

Kim CM, Yang HS, Boo H-J, Han GJ (2003) Surface treatment of metals using an atmospheric pressure plasma jet and their surface characteristics. Surf Coat Technol 174175:839-844. https://doi.org/10.1016/S0257-8972(03) 00560-7

Kiyokawa K, Itou A, Matsuoka H, Tomimatsu M, Sugiyama K (1999) Surface treatment of steel using non-equilibrium plasma at atmospheric pressure. Thin Solid Films 345:119-123. https://doi.org/10.1016/S0040-6090(99) 00064-4

Klarhöfer L, Viöl W, Maus-Friedrichs W (2010) Electron spectroscopy on plasma treated lignin and cellulose.
Holzforschung 64:331-336. https://doi.org/10.1515/HF. 2010.048

Klingner S, Voigts F, Viöl W, Maus-Friedrichs W (2013) Analysis of plasma degreased aluminium foil with XPS. Surf Eng 29(5):396-401. https://doi.org/10.1179/17432 94413Y.0000000129

Kogelschatz U (2000) Fundamentals and applications of dielectric-barrier discharges. In: HAKONE VII, international symposium on high pressure, low temperature plasma chemistry, vol 1, pp 1-7

Král P, Ráhel J, Stupavská M, Šrajer J, Klímek P, Mishra KP, Wimmer R (2015) XPS depth profile of plasma-activated surface of beech wood (Fagus sylvatica) and its impact on polyvinyl acetate tensile shear bond strength. Wood Sci Technol 49:319-330. https://doi.org/10.1007/ s00226-014-0691-7

Kuchenbecker M, Bibinov N, Kaemlimg A, Wandke D, Awakowicz P, Viöl W (2009) Characterization of DBD plasma source for biomedical applications. J Phys D 42:045212. https://doi.org/10.1088/0022-3727/42/4/045212

Lahmar A, Scudeller Y, Danes F, Bardon PJ (1995) X-ray photoelectron spectroscopy analysis of thermal and plasmatreated steel substrates and their interface formed with an aluminium layer. Thin Solid Films 226:58-61. https://doi. org/10.1016/0040-6090(95)06646-2

Latifi A, Imani M, Khorasani TM, Joupari DM (2014) Plasma surface oxidation of $316 \mathrm{~L}$ stainless steel for improving adhesion strength of silicone rubber coating to metal substrate. Appl Surf Sci 320:471-481. https://doi.org/10. 1016/j.apsusc.2014.09.084

Laux CO, Spence TG, Kruger CH, Zre RN (2003) Optical diagnostics of atmospheric pressure air plasmas. Plasma Sources Sci Technol 12:125-138. https://doi.org/10.1088/ 0963-0252/12/2/301

Lecoq E, Clément F, Panousis E, Loseau JF, Held B, Castetbon A, Guimon C (2008) Pinus Pinaster surface treatment realized in spatial and temporal afterglow DBD conditions. Eur Phys J Appl Phys 42(1):47-53. https://doi.org/ 10.1051/epjap:2008021

Lee CJ, Lee SK, Ko DC, Kim DJ, Kim BM (2009) Evaluation of surface and bonding properties of cold rolled steel sheet pretreated by $\mathrm{Ar} / \mathrm{O} 2$ atmospheric pressure plasma at room temperature. J Mater Process Technol 209:4769-4775. https://doi.org/10.1016/j.jmatprotec.2008.11.043

Levasseur O, Bouarouri A, Naudé N, Clergereaux R, Gherardi N, Stafford L (2014) Organization of dielectric barrier discharges in the presence of structurally inhomogenous wood substrates. IEEE Trans Plasma Sci 42(10):23662367. https://doi.org/10.1109/TPS.2014.2321518

Li Y, Wang L (2009) Study of oxidized layer formed on aluminium alloy by plasma oxidation. Thin Solid Films 517:3208-3210. https://doi.org/10.1016/j.tsf.2008.10.098

Lin J-W, Chang H-C (2011) Surface modification of SUS304 stainless steel by atmospheric pressure $\mathrm{Ar} / \mathrm{N}_{2} / \mathrm{O}_{2}$ plasma. Nucl Instrum Methods Phys Res Sect B 269:1801-1808. https://doi.org/10.1016/j.nimb.2011.05.004

Liu FP, Rials TG (1998) Relationship of wood surface energy to surface composition. Langmuir 14:536-541. https://doi. org/10.1021/la970573y

Machala Z, Janda M, Hensel K, Jedlovsky I, Lestinska L, Foltin V, Martisovits V, Morvova M (2007) Emission 
spectroscopy of atmospheric pressure plasmas for biomedical and environmental applications. J Mol Spectrosc 243:194-201. https://doi.org/10.1016/j.jms.2007.03.001

Mui TSM, Silva LLG, Prysiazhnyi V, Kostov KG (2017) Surface modification of aluminium alloys by atmospheric pressure plasma treatments for enhancement of their adhesion properties. Surf Coat Technol 312:32-36. https://doi. org/10.1016/j.surfcoat.2016.08.024

Nečasová B, Liška P, Kelar J, Šlanhof J (2019) Comparison of adhesive properties of polyurethane adhesive system and wood-plastic composites with different polymers after mechanical, chemical and physical surface treatment. Polymers 11(397):17p. https://doi.org/10.3390/polym 11030 397

Nguyen T, Cao Y, Zhou X, Dai Z, Nguyen Q (2016) Effects of plasma treatment on properties of poplar LVL. J For Eng 1(5):26-30

O'Connor DJ, Sexton BA, Smart RSC (2003) Surface analysis methods in materials science, 2nd edn. Springer, Berlin

Owens DK, Wendt RC (1969) Estimation of the surface free energy of polymers. J Appl Polym Sci 13(8):1741-1747. https://doi.org/10.1002/app.1969.070130815

Pancheshnyi S (2006) Comments on 'Intensity ratio of spectral bands of nitrogen as a measure of electric field strength in plasmas'. J Phys D 39:1708. https://doi.org/10.1088/00223727/39/8/N01

Paris P, Aints M, Valk F, Plank T, Haljaste A, Kozlov KV, Wagner H-E (2005) Intensity ratio of spectral bands of nitrogen as a measure of electric field strength in plasmas. J Phys D 38:3894. https://doi.org/10.1088/0022-3727/38/ $21 / 010$

Paris P, Aints M, Valk F, Plank T, Haljaste A, Kozlov KV, Wagner H-E (2006) Reply to comments on 'Intensity ratio of spectral bands of nitrogen as a measure of electric field strength in plasmas'. J Phys D 39:2636. https://doi.org/10. 1088/0022-3727/39/12/N01

Peng X, Zhang Z (2018) Plasma treatment of plastic film or decorative veneer and its effects on the peel strength and curling deformation of plastic film-reinforced pliable decorative sliced veneer (PR-RP-DSV). Holzforschung 73(3):313-322. https://doi.org/10.1515/hf-2018-0084

Peng X, Zhang Z (2019) Surface properties of different natural precious decorative veneers by plasma modification. Eur J Wood Wood Prod 77:125-137. https://doi.org/10.1007/ s00107-018-1355-3

Pitchford CL (2013) GEC plasma data exchange project. J Phys D 46:330301. https://doi.org/10.1088/0022-3727/46/33/ 330301

Polini W, Sorentino L (2003) Improving the wettability of 2024 aluminium alloy by means of cold plasma treatment. Appl Surf Sci 214:232-242

Pouzet M, Dubois M, Charlet K, Békou A, Leban JM, Baba M (2019) Fluorination renders the wood surface hydrophobic without any loss of physical and mechanical properties. Ind Crops Prod 133:133-141. https://doi.org/10.1016/j. indcrop.2019.02.044

Powell CJ, Jablonski A (2010) NIST Electron Inelastic-MeanFree-Path Database-Version 1.2, National Institute of Standards and Technology, Gaithersburg, MD

Prégent J, Vandsburger L, Blanchard V, Blanchet P, Riedl B, Sarkissian A, Stafford L (2015) Determination of active species in the modification of hardwood samples in the flowing afterglow of $\mathrm{N}_{2}$ dielectric barrier discharges open to ambient air. Cellulose 22:811-827. https://doi.org/10. 1007/s10570-014-0496-8

Prysiazhnyi V, Vasina P, Panyala NR, Havel J, Cernak M (2012) Air DCSBD plasma treatment of Al surface at atmospheric pressure. Surf Coat Technol 206:3011-3016. https://doi.org/10.1016/j.surfcoat.2011.12.039

Recek N (2019) Biocompatibility of plasma-treated polymeric implants. In: Mozetič M (ed) Surface modification to improve properties of materials MDPI. Basel, Switzerland, pp 257-276

Rodríguez-Villanueva C, Encinas N, Abenojar J, Martínez MA (2013) Assessment of atmospheric plasma treatment cleaning effect on steel surfaces. Surf Coat Technol 236:450-456. https://doi.org/10.1016/j.surfcoat.2013.10. 036

Šantak V, Zaplotnik R, Tarle Z, Milošević S (2015) Optical emission spectroscopy of an atmospheric pressure plasma jet during tooth bleaching gel treatment. Appl Spectrosc 69(11):1327-1333. https://doi.org/10.1366/15-07962

Sauerbier P, Anderson J, Gardner DJ (2018) Surface preparation and treatment for large-scale $3 \mathrm{D}$ printed composite tooling coating adhesion. Coatings 8(457):10p. https://doi. org/10.3390/coatings 8120457

Shen Q (2009) Surface properties of cellulose and cellulose derivatives: A review. In: Roman M (ed) Model cellulosic surfaces, 1st edn. American chemical society, Washington, pp 259-289

Stancu GD, Kaddouri F, Lacoste DA, Laux CO (2010) Atmospheric pressure plasma diagnostics by OES, CRDS and TALIF. J Phys D Appl Phys 43:124002. https://doi.org/10. 1088/0022-3727/43/12/124002

Steiger R, Gehri E, Widmann R (2006) Pull-off strength of axially loaded steel rods bonded in glulam parallel to the grain. Mater Struct 40:69-78. https://doi.org/10.1617/ s11527-006-9111-2

Strohmeier BR (1990) An ESCA method for determining the oxide thickness on aluminum alloys. Surf Int Anal 15:5156. https://doi.org/10.1002/sia.740150109

Talviste R, Galmiz O, Stupavská M, Tučeková Z, Kaarna K, Kováčik D (2019) Effect of DCSBD plasma treatment on surface properties of thermally modified wood. Surf Interfaces 16:8-14. https://doi.org/10.1016/j.surfin.2019.04. 005

Tang S, Kwon O-J, Lu N, Choi H-S (2005) Surface characteristics of AISI 304L stainless steel after an atmospheric pressure plasma treatment. Surf Coat Technol 195:298-306. https://doi.org/10.1016/j.surfcoat.2004.07.071

Tang S, Lu N, Myung S-W, Choi H-S (2006) Enhancement of adhesion strength between two AISI $316 \mathrm{~L}$ stainless steel plates through atmospheric pressure plasma treatment. Surf Coat Technol 200:5220-5228. https://doi.org/10. 1016/j.surfcoat.2005.06.020

Thomas M, Mittal KL (2013) Atmospheric pressure plasma treatment of polymers: relevance to adhesion. Scrivener Publishing LLC, Beverly, MA

Tlustochowicz G, Serrano E, Steiger R (2011) State-of-theart review on timber connections with glued-in steel rods. Mater Struct 44:997-1020. https://doi.org/10.1617/ s11527-010-9682-9 
Tóth A, Černákova L, Černák M, Kunovská K (2007) Surface analysis of groundwood paper treated by diffuse coplanar surface barrier discharge (DCSBD) type atmospheric plasma in air and in nitrogen. Holzforschung 61:528-531. https://doi.org/10.1515/HF.2007.080

Uzel M, Togay A, Anil Ö, Söğütlü C (2018) Experimental investigation on flexural behaviour of glulam beams reinforced with different bonding surface materials. Constr Build Mater 158:149-163. https://doi.org/10.1016/j.conbu ildmat.2017.10.033

Volgmann K, Voigts F, Maus-Friedrichs W (2010) The interaction of oxygen molecules with iron films studied with MIES, UPS and XPS. Surf Sci 604:906-913. https://doi. org/10.1016/j.susc.2010.02.018

Wagner H-E, Brandenburg R, Kozlov KV, Sonnenfeld A, Michel P, Behnke JF (2003) The barrier discharge: basic properties and applications to surface treatment. Vacuum 71:417-436. https://doi.org/10.1016/S0042-207X(02) 00765-0

Wascher R, Leike N, Avramidis G, Wolkenhauer A, Militz H, Viöl W (2015) Improved DMDHEU uptake of beech veneers after plasma treatment at atmospheric pressure. Eur J Wood Prod 73(4):433-437. https://doi.org/10.1007/ s00107-015-0916-y

Williams ST, Yu H, Yeh P-C, Yang J-M, Hicks FR (2014) Atmospheric pressure plasma effects on the adhesive bonding properties of stainless steel and epoxy composites. J Compos Mater 48(2):219-233. https://doi.org/10. $1177 / 0021998312470150$

Williams DF, Kellar ECJ, Jesson DA, Watts JF (2017) Surface analysis of 316 stainless steel treated with cold atmospheric plasma. Appl Surf Sci 403:240-247. https://doi. org/10.1016/j.apsusc.2017.01.150
Wolkenhauer A, Avramidis G, Hauswald E, Militz H, ViöL W (2009) Sanding vs. plasma treatment of aged wood: a comparison with respect to surface energy. Int J Adhes Adhes 28:18-22. https://doi.org/10.1016/j.ijadhadh.2007.11.001

Yu Y, Du Z, Chen M, Wang J (2008) Atmospheric-pressure dielectric-barrier discharge as a radiation source for optical emission spectrometry. Angew Chem Int Ed 47:7909_ 7912. https://doi.org/10.1002/anie.200802681

Zhang W, Cao Y, Yang P, Chen M, Zhou M (2019) Manufacturing and interfacial bonding behavior of plasma-treatedcarbon fiber reinforced veneer-based composites. Compos Struct 226:111203. https://doi.org/10.1016/j.compstruct. 2019.111203

Zhang W, Yang P, Cao Y, Yu P, Chen M, Zhou X (2020) Evaluation of fiber surface modification via air plasma on the interfacial behavior of glass fiber reinforced laminated veneer lumber composites. Constr Build Mater 233(117315):8p. https://doi.org/10.1016/j.conbuildmat.2019.117315

Žigon J, Petrič M, Dahle S (2019) Artificially aged spruce and beech wood surfaces reactivated using FE-DBD atmospheric plasma. Holzforschung 73(12):1069-1081. https:// doi.org/10.1515/hf-2019-0005

Žigon J, Kovač J, Zaplotnik R, Saražin J, Šernek M, Petrič M, Dahle S (2020) Supplemental material to manuscript "Enhancement of strength of adhesive bond between wood and metal using atmospheric plasma treatment" (Version 1.0.0) [Data set]. Zenodo. https://doi.org/10. 5281/zenodo.3662422

Publisher's Note Springer Nature remains neutral with regard to jurisdictional claims in published maps and institutional affiliations. 